\title{
Role of Mast Cells in the Control of Aldosterone Secretion
}

Authors

Antoine-Guy Lopez ${ }^{1,2^{*}}$, Céline Duparc ${ }^{{ }^{*}}$, Alexandre Naccache ${ }^{1,3}$, Mireille Castanet ${ }^{1,3}$, Hervé Lefebvre ${ }^{1,2 \S}$, Estelle Louiset ${ }^{1 \S}$

Affiliations

1 Normandie University, UNIROUEN, INSERM, DC2N, Rouen, France

2 Department of Endocrinology, Diabetes and Metabolic Diseases, Rouen University Hospital, Rouen, France

3 Department of Pediatrics, Rouen University Hospital, Rouen, France

Key words

adrenal cortex, aldosterone, aldosterone-producing

adenoma, mast cells, serotonin

received $\quad 20.12 .2019$

accepted $\quad 05.02 .2020$

Bibliography

DOI https://doi.org/10.1055/a-1119-1063

Published online: 25.3 .2020

Horm Metab Res 2020; 52: 412-420

(c) Georg Thieme Verlag KG Stuttgart . New York

ISSN 0018-5043

Correspondence

Hervé Lefebvre

Normandie Université, University Hospital of Rouen

UNIROUEN, INSERM U1239

76031 Rouen

France

Tel.: + 332328890 81, Fax: + 33232889154

herve.lefebvre@chu-rouen.fr

\section{ABSTRACT}

Mast cells are immune cells present in adrenals from various species. Proliferation and activation of adrenal mast cells seem to be influenced by environment, since they increase during summer and in response to sodium restriction in frogs and mouse, respectively. Although the physiological factors regulating adrenal mast cell activity have not been identified, they might involve neurotransmitters and the renin-angiotensin system. Some data indicate that adrenal mast cells stimulate proliferation of steroidogenic cells in the zona glomerulosa and activate the mineralocorticoid production. In human, mast cell degranulation stimulates aldosterone synthesis through the release of serotonin (5-HT) and activation of 5-HT4 receptors. Increase in mast cell population and upregulation of the 5-HT signaling pathway occur in aldosterone-producing adenomas. In particular, aldosterone-producing adenoma cells overexpress 5-HT4 receptors and are hyper-responsive to 5-HT4 receptor agonists. These data suggest that the intra-adrenal serotonergic regulatory system represents a potential target for development of both adrenal imaging methods to evaluate the lateralization of aldosterone production, and pharmacological treatments of primary aldosteronism.

\section{Introduction}

Aldosterone secretion by the human adrenal cortex is primarily regulated by the circulating renin angiotensin system (RAS) and plasma potassium [1]. However, in patients under long-term treatment with angiotensin converting enzyme inhibitors (ACEi) or angiotensin II receptor antagonists (ARA), plasma aldosterone concentrations usually re-increase after an initial decline [2,3]. This phenomenon, called "aldosterone breakthrough", has been designated as a potential factor to explain the reduction of the protective effect of ACEis and ARAs against the progression of heart failure and chronic nephropathy during long-term therapies [4]. In fact, it is now well established that aldosterone exerts profibrotic effects and

A-G.L. and C.D. contributed equally to this work

$\S \quad$ H.L. and E.L. share senior authorship triggers inflammation in the cardiovascular system and kidney [5], and antagonists at the mineralocorticoid receptor like spironolactone and eplerenone, have been shown to dramatically reduce mortality in patients with heart failure [6, 7]. The mechanism of aldosterone breakthrough is still unclear. Especially, no association between plasma aldosterone re-elevation and variations of plasma potassium and angiotensin II (Ang II) levels could be shown [4, 8]. Other regulatory systems which are not influenced by RAS inhibition, appear thus involved in the activation of the adrenal cortex during aldosterone breakthrough. In this regard, it is now well established that numerous factors, released in the adrenal gland, are able to modulate corticosteroid secretion. These paracrine signals, which have been extensively reviewed during the past years, can be produced by several cell types, including endothelial cells, chromaffin cells, and neurons $[9,10]$. Cells of the immune system, like 
macrophages and lymphocytes, which represent an important contingent of the cells that compose the adrenal cortex, are also capable of affecting corticosteroidogenesis [11]. In this review article, we will summarize our current knowledge on the role of mast cells in the regulation of aldosterone secretion in physiological and pathophysiological conditions.

\section{Mast cells in adrenal}

Mast cells are hematopoietic derived immune cells known for their role in the allergy and anaphylaxis processes [12]. Circulating mast cell precursors express the Kit tyrosine kinase receptor for the chemoattractant mast/stem cell growth factor (SCF) [13]. Under the influence of SCF produced in numerous organs, circulating precursors infiltrate tissues where they differentiate into mature mast cells. Resident mast cells are characterized by secretory granules containing various factors, including histamine, serotonin, heparin, cytokines and diverse proteases, such as tryptase, chymase, carboxypeptidase A3, and renin [14-17]. Mature mast cells are widely distributed throughout the body, especially in organs directly exposed to environment (skin, airways, and gastrointestinal tract) and in a lesser extent in the pancreas or cardiovascular system $[12,18,19]$. The presence of mast cells in the adrenal gland has also been reported in several animal species including human.

\section{Phylogenesis: From interrenal summer cells to adrenal mast cells}

Henri Stilling has shown as early as 1898 that the adrenal gland of the amphibians, that is, the so-called inter-renal gland, contains not only "lipidic" (steroidogenic) and chromaffin cells but also a third type of cells that he called "summer cells", their highest density being observed during summer [20]. These cells, which are now called Stilling's cells, are packed with dense and large metachromatic granules, which contain histamine and are thus considered as the amphibian counterpart of mammalian mast cells [21-23]. Interestingly, Stilling's cells establish close contacts with steroidogenic cells allowing direct interactions between the two cell types [24]. Mast cells have also been detected in mammal adrenals, in particular in the rat, guinea pig, mouse, and human [25-28]. Indeed, cells producing the mast cell-specific protease tryptase have been identified in the human adrenal cortex [29]. As in amphibians, mammalian mast cells have been detected in the vicinity of steroidogenic cells, especially in the subcapsular region of the mouse and human adrenals, suggesting the existence of intercellular communication between mast cells and aldosterone-producing cells ( $>$ Fig. 1) [27-29]. In addition, some mast cells are present in the wall of arterioles irrigating rat, guinea pig, mouse, and human adrenals ( $\mathbf{F i g}$. 1a, c) [25-27]. These perivascular mast cells have been shown to be involved in the control of adrenal blood flow in rat and cattle $[25,30]$. Globally, mast cells are present in adrenals of all studied species from amphibians to mammals.

\section{Regulation of adrenal mast cells}

Histological studies have demonstrated that mast cell proliferation in adrenals is a dynamic process, which varies according to physiological conditions. Indeed, as mentioned above, mast cell density increases in amphibian inter-renal glands during summer, when the animals are terrestrial after the breeding period in water. In ad- dition, an increase in water salinity affects the morphological appearance of mast cells in frog adrenals [31]. Interestingly, it has been noticed that in mice, mast cell infiltration in adrenals is dependent on strains and gender (more abundant in female), and augments with age [32]. As regards human fetal adrenal development, tryptase expression, which reflects activation of mast cells, raises during the third trimester of gestation, just preceding the appearance of aldosterone synthase expression [33]. This observation suggests that mast cells control differentiation of adrenocortical cells involved in mineralocorticoid production. Altogether, these data indicate that proliferation and activation of mast cells in adrenals is a physiological process regulated by both genetic background and environmental factors.

Differentiation of resident mast cells is markedly influenced by cellular microenvironment. Especially, mature mast cells display different sensitivities to regulatory factors depending on their tissue location. These bioactive signals include numerous neurotransmitters, neuropeptides and hormones, which can stimulate degranulation of mast cells [17]. However, the physiological factors that regulate mast cell activity in adrenal glands have not been clearly established. The observation that, in human, nerve fibers establish contacts on adrenal mast cells is indicative of their control by the autonomous nervous system [29] ( adrenal mast cells are responsive to the pituitary hormone corticotrophin (ACTH), suggesting that they may participate to the adrenal response to stress [34]. Rat adrenal mast cells also express angiotensin 2 receptors (AT2R), supporting a potential influence of RAS on this cell type [35]. This hypothesis has been reinforced by the recent observation that low sodium diet, which activates RAS, upregulates adrenal expression of Tpsb2 encoding the mast cell-specific protease tryptase, in both BALB/C and C57BI6 mice [27]. It can be noticed that there is currently no evidence for a putative control of mast cells by ACTH or Ang II in the human adrenal.

\section{Potential role of mast cell on adrenal growth}

Some reports have suggested that adrenal mast cells might promote proliferation of steroidogenic cells. In fact, it has been observed that the highest densities of mast cells are both concomitant with amphibian adrenal hypertrophy during summer and associated with subcapsular adrenal cell hyperplasia in different mouse strains like the IQI/Jic strain [20,32, 36]. Mast cell-deficient mice (Kit ${ }^{\mathrm{W}-\mathrm{sh} / \mathrm{W} \text {-sh }}$ ) exhibit normal adrenal morphology but it is conceivable that, in this model, the absence of mast cells may be compensated by activation of other proliferative signals [27]. Especially, mast cell-deficient mice exhibit overexpression of the adrenal RAS, an autocrine/paracrine system which is known to favor ZG hypertrophy [37]. It would be thus interesting to further examine the role of mast cells on adrenal expansion in mammals, in particular by performing xenograft of both human mast cells and adrenocortical cells under the renal capsule of adrenalectomized immunodeficient mice [38].

\section{Mast cells control aldosterone secretion}

Concomitance of adrenal mast cell proliferation and elevation of plasma aldosterone concentrations in amphibians during summer reported in the 1960s, was highly suggestive of a role of mast cells in the control of steroidogenesis ( $\triangleright$ Fig. 2). This assumption has re- 


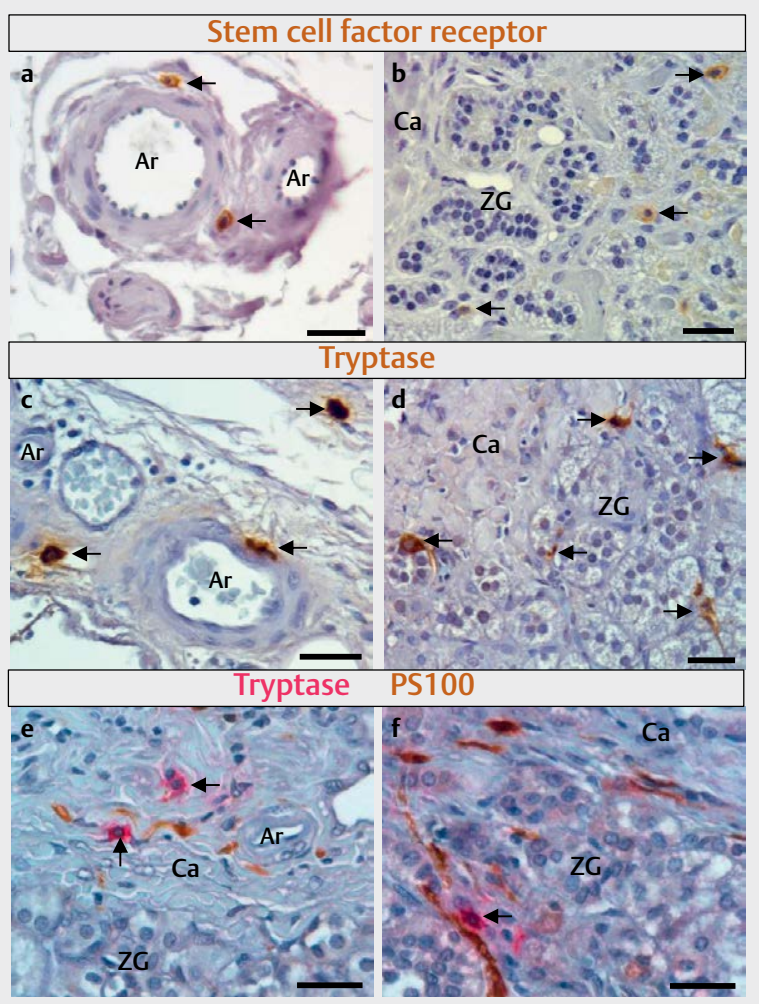

- Fig. 1 Distribution of mast cells in the human adrenal: a-d, Presence of mast cells closed to arteries ( $\mathrm{Ar}$ ) irrigating adrenals $\mathbf{a}, \mathbf{c}$ and in the zona glomerulosa (ZG; $\mathbf{b}, \mathbf{d}$ ) of the adrenal cortex revealed by immunohistochemistry using antibodies against the receptor of the stem cell factor (CD117; a, b) and the mast cell specific protease tryptase c, d. e, f: Innervation of mast cells revealed by double immunolabeling using antibodies against tryptase (pink) and protein S100 (PS100; brown), a marker of myelinated nerves, in the vicinity of arteries and in ZG. Immunoreactive mast cells are indicated by arrows. Ca: Capsule. Scale bar $=50 \mu \mathrm{m}$.
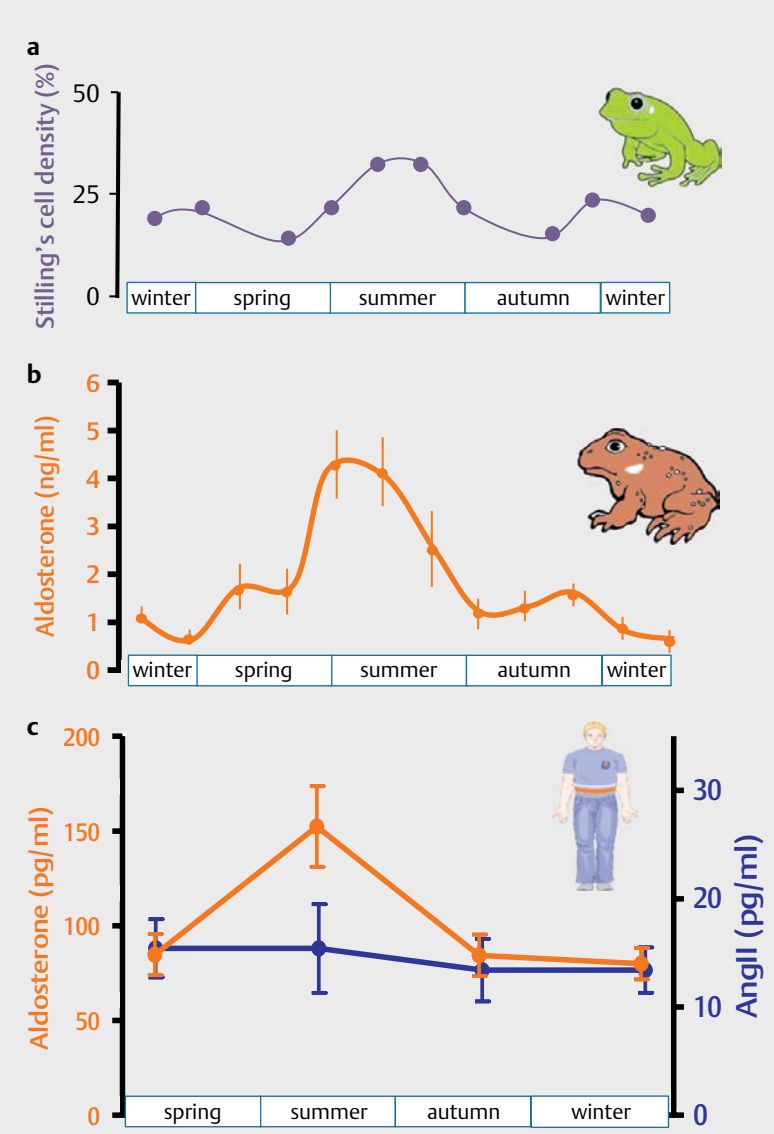

- Fig. 2 Season variations of adrenal mast cell density and plasma aldosterone concentrations in amphibians and human: a Circannual variation of adrenal Stilling's cell (amphibian mast cell) density in the frog Rana ridibunda (data from [65]). b Circannual variation of plasma aldosterone levels in the toad Bufo japonicas formosus (data from [98]). c Seasonal variations of plasma aldosterone and angiotensin II (Ang II) concentrations in human (data from [39]). cently been reinforced by data obtained in mouse models. Indeed, a positive correlation between expression of genes encoding respectively tryptase (Tpsb2) and aldosterone synthase (Cyp11b2) has been observed in adrenals of BALB/C and C57BL/6 mice [27]. Moreover, concurrent upregulations of tryptase and aldosterone synthase have been detected in adrenal mice in response to sodium restriction. These data may suggest the existence of a common mechanism of regulation of the two genes or an interdependent relationship between mast and adrenocortical cell types. The latter hypothesis is supported by the observation that mast cell-deficient mice show a dysregulation of aldosterone secretion [27]. In fact, although Kit ${ }^{W-s h} / \mathrm{W}-\mathrm{sh}$ and wild type mice display similar plasma and urine aldosterone levels under normal sodium diet, mast cell-deficient mice develop an exaggerated aldosterone response to low sodium diet. This unexpected hyperaldosteronism seems to result from adrenal renin and angiotensin type 1 receptor overexpression [27]. Activation of adrenal RAS may represent a compensatory mechanism aimed at stimulating aldosterone secretion in the absence of mast cells. It is not known whether similar compen- satory system can also be activated in human adrenal to supply mast cell dysfunction, in particular in patients with mast cell deficiency due to inactivating KIT mutation (i. e. patients with piebaldism) or those treated with mast cell stabilizers to prevent allergic disorders. Globally, all these data indicate that adrenal mast cells promote mineralocorticoid secretion in concert with circulating RAS. The observation that human plasma aldosterone reaches maximum levels in summer while plasma Ang II show no seasonal variations [39] ( $\vee$ Fig. 2b), suggests that, in humans as in amphibians, mast cells might play a role in control of mineralocorticoid production to optimally adapt the hydromineral homeostasis to sweating due to warm environment temperatures.

Paracrine control of mast cells on aldosterone-producing cells has also been investigated by ex vivo experiments. It was shown that degranulation of resident mast cells induced by compound $48-80$, increases aldosterone production by perfused rat adrenals or perifused explants of human adrenals $[25,40]$. In very much the same way, in vitro experiments have revealed that mast cell secre- 
tory products enhance transcription of CYP11B2 and aldosterone synthesis by the human adrenocortical cell line H295R [29].

\section{Serotonin secreted by mast cells stimulates aldosterone synthesis}

Mast cells have the capacity to respond to stimulatory signals by the release of various biologically active mediators, including histamine, heparin, serotonin (5-HT), cytokins and various neurohormones. By inducing vasorelaxation and increase in adrenal blood flow, histamine stimulates aldosterone secretion in rat, bovine and $\operatorname{dog}[25,30,41]$. Although expression of histamine type 1 receptor has been detected in the human zona glomerulosa [42], there is no clear evidence for a direct control of histamine on steroidogenesis. Indeed, some contradictory data reported that histamine augment, inhibit or do not affect aldosterone synthesis in rat, bovine or human $[25,30,43,44]$.

The effect of heparin on the mineralocorticoid production is poorly documented in the literature. Nevertheless, Oster et al. have reported that heparin reduces plasma and urine aldosterone levels in rat and human [45]. They have also stated that prolonged treatment of patients with the anticoagulant decreases the sensitivity of aldosterone-producing cells to Ang II. Mast cells have also the ability to release renin [46] but, to our knowledge, renin production by intra-adrenal mast cells has never been investigated.

In the opposite, the involvement of 5-HT in the control of adrenal steroidogenesis has been extensively documented. First, it has been demonstrated that human mast cells express tryptophan hydroxylase type 1 (Tph1), the rate-limiting enzyme synthesizing 5-HT from tryptophan [47]. Second, the presence of 5-HT in adrenal mast cells has been evidenced by histological studies $[28,47]$. Third, in vitro experiments conducted on human adrenal explants have demonstrated that mast cell degranulation provokes the release of 5-HT which in turn stimulates aldosterone production ( Fig. 3) [40]. The decrease in the aldosterone response of adrenocortical H295R cells to mast cell-secretory products by concomitant application of 5-HT receptor antagonists has confirmed the crucial role of 5-HT in the paracrine communication between the two cell types [29]. Finally, it has been shown that 5-HT stimulates aldosterone synthesis by isolated adrenocortical cells from frog, rat, and human adrenals [28,48].

Studies on the mechanism of action of 5-HT have revealed that the steroidogenic response to the amine is relayed by activation of 5-HT type 4 receptors (5-HT4) in frog and human adrenals ( $>$ Fig. 3), whereas it involves 5-HT type 7 receptors (5-HT7) in rat [48-50]. Expression of 5-HT4 receptor in human zona glomerulosa cells has been confirmed by histological studies [47, 51, 52]. In agreement with these data, clinical trials have demonstrated that 5-HT4 receptor agonists (metoclopramide, cisapride, zacopride) or 5-HT reuptake inhibitors increase plasma aldosterone levels [50,53-56]. In all studied species, adrenal 5-HT receptors are positively coupled to the AMPc/protein kinase A pathway and membrane calcium channels [57-59], which are important signaling pathways for the stimulation of steroidogenesis [1].

Up to now, the physiological conditions that activate 5 - $\mathrm{HT}$ release by intra-adrenal mast cells remain to be identified. Since mouse adrenal mast cells are activated by sodium restriction, it would be relevant to evaluate whether the 5 -HT synthesizing enzyme Tph 1 is dif-

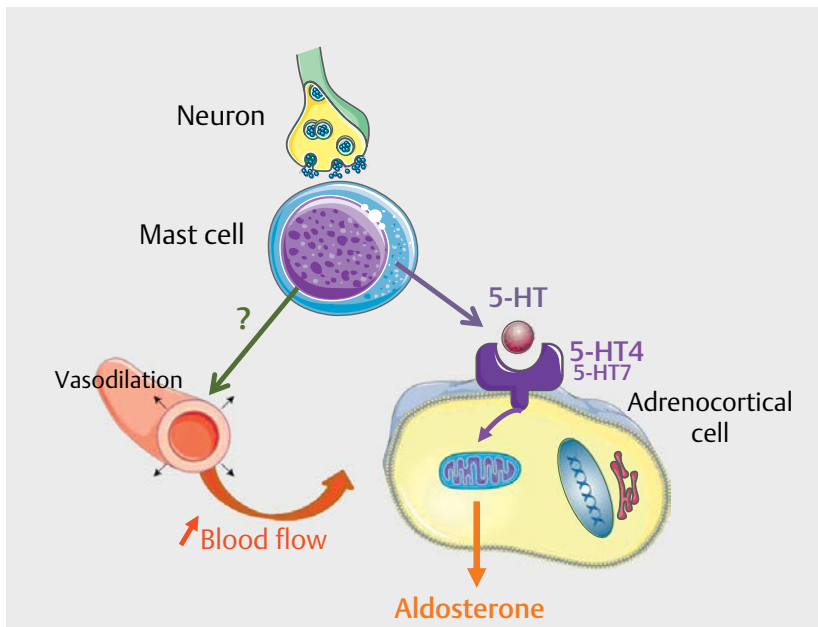

- Fig. 3 Adrenal mast cells control aldosterone secretion through direct and indirect effects in physiological conditions: Adrenal mast cells are innervated by fibers of the autonomic nervous system. In response to neural inputs, they are capable of releasing numerous bioactive factors including biogenic amines and cytokines, which can modulate the adrenal vascular tone and steroidogenesis. In this way, degranulation of mast cells provokes vasodilation and a consecutive increase in adrenal blood flow which indirectly stimulates aldosterone secretion by adrenocortical cells. In addition, mast cells release serotonin (5-HT) which directly activates aldosterone synthesis via activation of 5-HT4 receptors in frog and human, and 5-HT7 receptors in rat.

ferentially expressed in adrenal from mice under normal and low sodium diets. The impact of sodium depletion or pharmacological inhibition of RAS on 5-HT release by adrenal mast cells might also be indirectly estimated by examining aldosterone production in mice with selective Tph1 deficiency in mast cells (Kit ${ }^{\mathrm{Tph} 1-/-}$ mouse model [60]) in comparison with wild type or Kit ${ }^{\mathrm{W}-s h / W-s h}$ animals.

It will be interesting to study involvement of adrenal 5-HT receptors in the adaptation of mineralocorticoid synthesis to different physiological conditions, especially in 5-HT7 receptor-deficient rats [61] or in wild type animals and healthy volunteers treated with 5-HT7 and 5-HT4 receptor antagonists, respectively. In this regard, it has been reported that treatment of healthy volunteers with piboserod, a 5-HT4 receptor antagonist, abolished the plasma aldosterone response to the 5-HT4 receptor agonist cisapride [62]. However, this clinical trial was not designed for examining the effect of piboserod on basal aldosterone secretion nor in response to orthostatism and sodium restriction, which are physiological conditions stimulating the mineralocorticoid production. Unfortunately, piboserod is no more available for clinical use hampering thus further in vivo investigations. We have tried to overcome this difficulty by using I-lysine, which acts as a partial 5-HT4 receptor antagonist [63]. We found that diet enriched in this amino acid $(5-8 \mathrm{~g} /$ day) did not modify plasma aldosterone levels in healthy subjects in supine and upright positions, or under low sodium diet [64]. The lack of effect of I-lysine on aldosterone production could be ascribed to the low efficiency of the amino acid to antagonize activation of 5-HT4 receptor. Indeed, food supplementation with I-lysine 
only weakly reduced the plasma aldosterone increase induced by administration of the 5-HT4 receptor agonist metoclopramide [64]. Development of other potent 5-HT4 receptor antagonists which can be administered in humans is therefore required to explore the contribution of 5-HT in the paracrine control of the mineralocorticoid production by mast cells.

Other bioactive signals may be involved in the steroidogenic cell/mast cell interaction such as endozepins in the frog inter-renal gland or cytokine like IL-6 in the mammalian adrenal [65-67].

\section{Mast cells in pathophysiology of hyperaldosteronism}

Resident mast cells have been observed in many organs. Interestingly, their density has been shown to increase in various pathological conditions $[14,18,19]$. Consequently, the role of mast cells in pathogenesis has become a subject of raising interest. Especially, a growing body of evidence indicates that mast cells are implicated in tumor development [68-73]. Indeed, these cells are known to favor immunologic tolerance and secrete both growth and angiogenic factors which enhance tumor expansion [74-76]. Notably, a positive effect of mast cells has been observed on growth of endocrine neoplasias, including neuroendocrine tumors of thyroid, pancreas, and adrenal (pheochromocytomas) [77-79]. In 1985, Aiba et al. detected for the first time mast cell infiltration in an adrenocortical tumor producing deoxycorticosterone [80]. They have also observed mast cell infiltration in aldosterone-producing adenomas (APAs) but not in cortisol-secreting adenomas. Subsequently, an increase in mast cell population has been confirmed in a large series of APAs ( $>$ Fig. 4) [29]. This process can be ascribed to the diffuse expression of SCF, the mast cell growth factor, in adenoma tissues [29]. Furthermore, transcriptomic analysis have revealed that mast cell gene expression levels discriminates APA tissues from normal adrenals [29]. This observation may be regarded as a molecular signature of mast cell hyperplasia in APA tissues. Altogether, these data suggest that mast cells facilitate proliferation of glomerulosa cells and aldosterone synthesis.

Globally, two profiles of distribution of mast cells have been identified in APAs. In the majority of tissues, mast cells are mainly visualized in the peritumoral cortex adjacent to adenoma. This distribution of mast cells is more frequently observed in female patients and in the largest tumors. This finding is consistent with the fact that peritumoral mast cells are more efficient to enhance tumor expansion than intratumoral mast cells [81]. In this subtype of APAs, nerve fibers establish connections on mast cells located in periadenoma tissues [29], suggesting that, as in the normal adrenal gland, the autonomous nervous system might indirectly control aldosterone biosynthesis via activation of mast cells. In support of this hypothesis, it has been noticed that the distribution of the aldosterone synthetizing enzyme is correlated with the presence of mast cells in peritumoral cortex but not in adenomas. Indeed, mast cells present in the subcapsular region of peritumoral tissues are associated with aldosterone-producing cell clusters (APCC) in the zona glomerulosa [29]. Thus, mast cells might contribute to the previously shown persistence of aldosterone synthesis in peritumoral tissue [82]. A second subtype of APAs, characterized by a highest mast cell density in adenoma, displays predominant expression of aldosterone synthase in tumors [29]. In these patients, both plasma aldosterone and aldosterone/renin ratio levels corre-

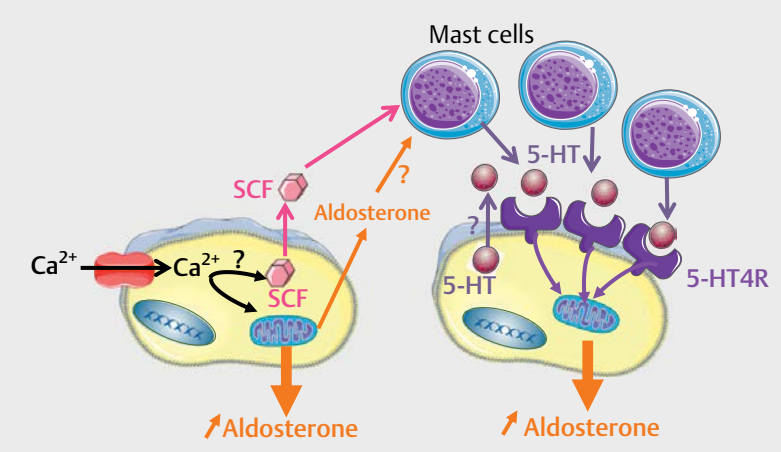

-Fig. 4 Putative role of mast cells in the pathophysiology of primary aldosteronism: Aldosterone-producing adenomas (APAs) are associated with mast cell hyperplasia, likely in response to overproduction of stem cell factor (SCF; the mast cell growth factor) by adenoma cells. Increased SCF expression may result from the elevation of cytosolic calcium concentration consecutive to somatic mutations of membrane ion channels and ATPases. Mobilization of the calcium signaling pathway is also known to stimulate aldosterone production through expression of aldosterone synthase. In fine, the increase in mast cell density, together with ectopic production of 5-HT by a subpopulation of steroidogenic cells, lead to enhancement of the local serotonergic tone in APA tissues. The elevation of intra-adrenal 5-HT production is concomitant with overexpression of 5-HT4 receptors by aldosterone-producing cells. The global enhancement of the mast cell/5-HT regulatory system may contribute to the pathophysiology of primary aldosteronism in patients with APAs.

late with the tumor mast cell density. These findings indicate that intra-adenomatous mast cells activate aldosterone biosynthesis by adenoma cells. Altogether, these data suggest that mast cells contribute to the pathogenesis of APA with proliferative and steroidogenic effects depending on their localization.

Recent genetic analyses have revealed that APAs are frequently associated with somatic mutations of KCNJ5, CACNA1D, ATP1A1 or ATP2B3 genes, encoding membrane ionic channels or ATPases [83]. All these mutations promote an increase in calcium signaling pathway, the main trigger for aldosterone production [83, 84]. It is not known whether the somatic mutations responsible for aldosterone overproduction may also influence mast cell infiltration in APA tissues. The preferential distribution of mast cells in adenomas versus peritumoral tissue does not seem to be influenced by the CACNA1D or KCNJ5 mutational status but this observation would have to be confirmed in larger series of APAs. However, it is noteworthy that mast cell density in adenoma has been reported to be higher in CACNA1D-mutated APAs than in other tumors [29]. It can thus be hypothesized that elevation of calcium concentration in steroidogenic CACNA1D-mutated cells might upregulate expression of SCF reinforcing mast cell chemoattraction in adrenal lesions. In support of this assumption, it has been reported that the L-type calcium channel blocker nifedipine reduces expression of SCF and lowers cardiac mast cell density in a mouse model of viral myocarditis [85]. It is also conceivable that aldosterone overproduction may activate adrenal mast cells, since this cell type is known to express the mineralocorticoid receptor $[86,87]$. Consistently, epler- 
enone, a selective aldosterone receptor antagonist, inhibits expression of mast cell proteases in the mouse myocardium [87]. Taken collectively, these findings suggest that mutations responsible for an increase in cytosolic calcium concentration in aldosterone-producing cells might lead to mast cell hyperplasia and the development of an intra-adrenal amplification loop reinforcing aldosterone production.

The increase in mast cell density in APA tissues may reinforce the intra-adrenal production of 5-HT ( $>$ Fig. 4). In addition, a subpopulation of steroidogenic cells able to synthesize 5 -HT has been identified in APAs, that may further enhance the 5-HT-ergic control of aldosterone synthesis [52]. The increase in local production of $5-\mathrm{HT}$ is not the sole pathological event affecting the serotonergic signaling pathway in APAs. In fact, some in vitro experiments have shown that adenoma cells are hypersensitive to 5-HT and 5-HT4 receptor agonists [88]. Hyper-responsiveness to 5-HT4 receptor ligands has been ascribed to overexpression of 5-HT4 receptors in APAs [52, 89-92]. Upregulation of HTR4, the gene encoding the 5-HT4 receptor, may be due to hypomethylation of its promoter region [92]. Hypersensitivity of tumor cells to 5-HT may also be explained by abnormal HTR4 mRNA splicing resulting in expression of 5-HT4 receptor isoforms different from those detected in normal adrenals [52]. In agreement with these data, clinical trials have demonstrated that the 5 -HT4 receptor agonists cisapride, metoclopramide and tegaserod provoke exaggerated plasma aldosterone responses in patients with APAs in comparison with healthy volunteers [55, 88, 89, 93, 94]. Collectively, these data indicate that the intra-adrenal release of 5 -HT by mast cells and steroidogenic cells contribute to the pathophysiology of primary aldosteronism in patients with APAs.

\section{Perspectives}

Identification of the mast cell/5-HT regulatory pathway in the adrenal cortex offers new interesting perspectives for the clinical management of primary aldosteronism. Especially, some data suggest that the 5-HT4 receptor may represent a valuable target for the development of innovative adrenal imaging methods aimed at determining the source (i. e., unilateral versus bilateral) of aldosterone excess. In fact, in patients who underwent unilateral adrenalectomy for APA, administration of the 5 -HT4 receptor cisapride shortly after surgery has no effect on plasma aldosterone levels [88]. It seems thus that the 5 -HT4 receptor is repressed or not functional in the adrenal controlateral to the tumor. Consequently, administration of radiolabeled specific 5 -HT4 receptor agonists to patients with APA may show unilateral adrenal uptake. However, the question is whether adrenal glands may actually be viewable through this approach. In this regards, radiolabeled 5-HT4R ligands have successively been used for positron emission tomography (PET) scan imaging in monkeys and humans [95, 96]. Interestingly, monkey adrenals have been well visualized in whole-body PET images [97] but such observations are still lacking in man.

Finally, upregulation of the 5-HT signaling pathway in APA tissues also suggests that counteracting the synthesis of 5-HT by using a tryptophan hydroxylase inhibitor, or reducing the action of 5-HT with new 5-HT4 receptor antagonists may represent potential therapeutic approaches to decrease aldosterone production in patients with primary aldosteronism.

\section{Funding Information}

This work was supported by the Institut National de la Santé et de la Recherche Médicale, the Conseil Régional de Normandie and the European Regional Development Fund program Steroids.

\section{Acknowledgements}

We are indebted to Dr. Françoise Gobet and Guillaume Defortescu for their collaboration. We thank Elodie Colas for her skilful technical assistance. Images were obtained on PRIMACEN, the Cell Imaging Platform of Normandy, University of Rouen.

\section{Conflict of Interest}

A. Naccache was a recipient of a doctoral grant from Sandoz Laboratories. M. Castanet was investigator for clinical trials sponsored by Sandoz, Nestlé, Merck Serono and Novo-Nordisk Laboratories and received payments for her participation in a Sanofi Laboratory board. H. Lefebvre received payments for lectures from MSD and Novo-Nordisk Laboratories as well as travel grants from IPSEN, Novartis and Pfizer Laboratories. $\mathrm{H}$. Lefebvre was also investigator for clinical trials sponsored by Novartis Laboratories and received research grants by Novartis Laboratories.

\section{References}

[1] Bollag WB. Regulation of aldosterone synthesis and secretion. Compr Physiol 2014; 4: 1017-1055

[2] Staessen ], Lijnen P, Fagard R et al. Rise of plasma aldosterone during long-term captopril treatment. N Engl J Med 1981; 304: 1110

[3] Bomback AS, Rekhtman Y, Klemmer PJ et al. Aldosterone breakthrough during aliskiren, valsartan, and combination (aliskiren + valsartan) therapy. J Am Soc Hypertens JASH 2012; 6: 338-345

[4] Schjoedt KJ, Andersen S, Rossing P et al. Aldosterone escape during blockade of the renin-angiotensin-aldosterone system in diabetic nephropathy is associated with enhanced decline in glomerular filtration rate. Diabetologia 2004; 47: 1936-1939

[5] Briet M, Schiffrin EL. Aldosterone: effects on the kidney and cardiovascular system. Nat Rev Nephrol 2010; 6: 261-273

[6] Pitt B, Zannad F, Remme WJ et al. The effect of spironolactone on morbidity and mortality in patients with severe heart failure. Randomized Aldactone Evaluation Study Investigators. N Engl J Med 1999; 341: 709-717

[7] Zannad F, McMurray JJV, Krum H et al. Eplerenone in patients with systolic heart failure and mild symptoms. N Engl J Med 2011; 364: $11-21$

[8] Sato A, Saruta T. Aldosterone escape during angiotensin-converting enzyme inhibitor therapy in essential hypertensive patients with left ventricular hypertrophy. J Int Med Res 2001; 29: 13-21

[9] Ehrhart-Bornstein M, Hinson JP, Bornstein SR et al. Intraadrenal interactions in the regulation of adrenocortical steroidogenesis. Endocr Rev 1998; 19: 101-143

[10] Lefebvre H, Prévost G, Louiset E. Autocrine/paracrine regulatory mechanisms in adrenocortical neoplasms responsible for primary adrenal hypercorticism. Eur J Endocrinol 2013; 169: R115-R138

[11] Nussdorfer GG, Mazzocchi G. Immune-endocrine interactions in the mammalian adrenal gland: Facts and hypotheses. Int Rev Cytol 1998; 183: $143-184$

[12] Theoharides TC, Valent P, Akin C. Mast cells, mastocytosis, and related disorders. N Engl J Med 2015; 373: 163-172 
[13] Shamloo A, Manchandia M, Ferreira M et al. Complex chemoattractive and chemorepellent Kit signals revealed by direct imaging of murine mast cells in microfluidic gradient chambers. Integr Biol Camb 2013; 5: 1076-1085

[14] Veerappan A, Reid AC, Estephan R et al. Mast cell renin and a local renin-angiotensin system in the airway: Role in bronchoconstriction. Proc Natl Acad Sci USA 2008; 105: 1315-1320

[15] Gilfillan AM, Austin SJ, Metcalfe DD. Mast cell biology: Introduction and overview. Adv Exp Med Biol 2011; 716: 2-12

[16] de Souza Junior DA, Santana AC, da Silva EZM et al. The role of mast cell specific chymases and tryptases in tumor angiogenesis. BioMed Res Int 2015; 2015: 142359

[17] Theoharides TC. Neuroendocrinology of mast cells: Challenges and controversies. Exp Dermatol 2017; 26: 751-759

[18] Shi G-P, Bot I, Kovanen PT. Mast cells in human and experimental cardiometabolic diseases. Nat Rev Cardiol 2015; 12: 643-658

[19] Martino L, Masini M, Bugliani M et al. Mast cells infiltrate pancreatic islets in human type 1 diabetes. Diabetologia 2015; 58: 2554-2562

[20] Stilling H. Zur Anatomie der Nebennieren. Arch Mikr Anat 1898; 52: 176-195

[21] Volk TL. Morphologic observations on the summer cell of Stilling in the interrenal gland of the American bullfrog (Rana catesbeiana).

Z Zellforsch Mikrosk Anat 1972; 130: 1-11

[22] Kawamura K. Occurrence and release of histamine-containing granules in summer cells in adrenal glands of the frog Rana catesbeiana. J Anat 1986; 148: 111-119

[23] Regueira E, Scaia MF, Volonteri MC et al. Anteroposterior variation of the cell types in the interrenal gland of the male toad Rhinella arenarum (Amphibia, Anura). J Morphol 2013; 274: 331-343

[24] Accordi F, Cianfoni P. Histology and ultrastructure of the adrenal gland of Rhacophorus leucomystax (Amphibia, Anura). Bull Zool 1981; 48: 277-284

[25] Hinson JP, Vinson GP, Pudney J et al. Adrenal mast cells modulate vascular and secretory responses in the intact adrenal gland of the rat. | Endocrinol 1989; 121: 253-260

[26] Panula P, Kaartinen M, Mäcklin M et al. Histamine-containing peripheral neuronal and endocrine systems. J Histochem Cytochem 1985; 33: 933-941

[27] Boyer H-G, Wils ], Renouf S et al. Dysregulation of aldosterone secretion in mast cell-deficient mice. Hypertension 2017; 70: $1256-1263$

[28] Lefebvre $\mathrm{H}$, Contesse V, Delarue $\mathrm{C}$ et al. Serotonin-induced stimulation of cortisol secretion from human adrenocortical tissue is mediated through activation of a serotonin 4 receptor subtype. Neuroscience 1992; 47: 999-1007

[29] Duparc C, Moreau L, Dzib JFG et al. Mast cell hyperplasia is associated with aldosterone hypersecretion in a subset of aldosterone-producing adenomas. J Clin Endocrinol Metab 2015; 100: E550-E560

[30] Zhang DX, Gauthier KM, Campbell WB. Mechanisms of histamine-induced relaxation in bovine small adrenal cortical arteries. Am J Physiol Endocrinol Metab 2005; 289: E1058-E1063

[31] Scheer BT, Wise PT. Changes in the Stilling cells of frog interrenals after hypophysectomy and exposure to hypertonic saline solution. Gen Comp Endocrinol 1969; 13: 474-477

[32] Kim JS, Kubota H, Kiuchi Y et al. Subcapsular cell hyperplasia and mast cell infiltration in the adrenal cortex of mice: comparative study in 7 inbred strains. Exp Anim 1997; 46: 303-306

[33] Naccache A, Louiset E, Duparc C et al. Temporal and spatial distribution of mast cells and steroidogenic enzymes in the human fetal adrenal. Mol Cell Endocrinol 2016; 434: 69-80
[34] Hinson JP, Vinson GP, Kapas S et al. The relationship between adrenal vascular events and steroid secretion: the role of mast cells and endothelin. J Steroid Biochem Mol Biol 1991; 40: 381-389

[35] Carvalho RF, Ribeiro RA, Falcão RA et al. Angiotensin II potentiates inflammatory edema in rats: Role of mast cell degranulation. Eur J Pharmacol 2006; 540: 175-182

[36] Nakamura M. The seasonal variations in the adrenal cortex cells of bullfrog, with special remark to the origination of the summer cell. Endocrinol Jpn 1967; 14: 43-59

[37] Nogueira EF, Bollag WB, Rainey WE. Angiotensin II regulation of adrenocortical gene transcription. Mol Cell Endocrinol 2009; 302: 230-236

[38] Mazzuco TL, Chabre O, Feige J-J et al. Aberrant expression of human luteinizing hormone receptor by adrenocortical cells is sufficient to provoke both hyperplasia and Cushing's syndrome features. J Clin Endocrinol Metab 2006; 91: 196-203

[39] Kanikowska D, Sugenoya J, Sato M et al. Influence of season on plasma antidiuretic hormone, angiotensin II, aldosterone and plasma renin activity in young volunteers. Int J Biometeorol 2010; 54: 243-248

[40] Lefebvre H, Compagnon P, Contesse V et al. Production and metabolism of serotonin (5-HT) by the human adrenal cortex: paracrine stimulation of aldosterone secretion by 5-HT. J Clin Endocrinol Metab 2001; 86: 5001-5007

[41] Aikawa T, Hirose T, Matsumoto I et al. Direct stimulatory effect of histamine on aldosterone secretion of the perfused dog adrenal gland. Jpn J Physiol 1981; 31: 457-463

[42] Szabó PM, Wiener Z, Tömböl Z et al. Differences in the expression of histamine-related genes and proteins in normal human adrenal cortex and adrenocortical tumors. Virchows Arch Int J Pathol 2009; 455: 133-142

[43] Orsó E, Szalay KS, Tóth IE et al. Effect of histamine on corticosteroid secretion of isolated human and rat adrenocortical cells. Inflamm Res 1995; 44: (Suppl 1) S48-S49

[44] Pagotto RM, Pereyra EN, Monzón C et al. Histamine inhibits adrenocortical cell proliferation but does not affect steroidogenesis. J Endocrinol 2014; 221: 15-28

[45] Oster JR, Singer I, Fishman LM. Heparin-induced aldosterone suppression and hyperkalemia. Am J Med 1995; 98: 575-586

[46] Aldi S, Robador PA, Tomita K et al. IgE receptor-mediated mast-cell renin release. Am J Pathol 2014; 184: 376-381

[47] Bram Z, Louiset E, Ragazzon B et al. PKA regulatory subunit 1A inactivating mutation induces serotonin signaling in primary pigmented nodular adrenal disease. J Clin Investig. Insight 2016; 1 : e87958

[48] Contesse V, Lefebvre $\mathrm{H}$, Lenglet $\mathrm{S}$ et al. Role of $5-\mathrm{HT}$ in the regulation of the brain-pituitary-adrenal axis: Effects of 5-HT on adrenocortical cells. Can J Physiol Pharmacol 2000; 78: 967-983

[49] Contesse V, Lenglet S, Grumolato L et al. Pharmacological and molecular characterization of 5-hydroxytryptamine(7) receptors in the rat adrenal gland. Mol Pharmacol 1999; 56: 552-561

[50] Lefebvre $\mathrm{H}$, Contesse V, Delarue $\mathrm{C}$ et al. Effect of the serotonin-4 receptor agonist zacopride on aldosterone secretion from the human adrenal cortex: In vivo and in vitro studies. J Clin Endocrinol Metab 1993; 77: 1662-1666

[51] Le Mestre ], Duparc C, Reznik Y et al. Illicit upregulation of serotonin signaling pathway in adrenals of patients with high plasma or intraadrenal ACTH levels. J Clin Endocrinol Metab 2019; 104: 4967-4980

[52] Cartier D, Jégou S, Parmentier F et al. Expression profile of serotonin4 (5-HT4) receptors in adrenocortical aldosterone-producing adenomas. Eur J Endocrinol 2005; 153: 939-947 
[53] Edwards CR, Al-Dujaili EA, Boscaro M et al. In vivo and in vitro studies on the effect of metoclopramide on aldosterone secretion. Clin Endocrinol (Oxf) 1980; 13: 45-50

[54] Pratt JH, Ganguly A, Parkinson CA et al. Stimulation of aldosterone secretion by metoclopramide in humans: Apparent independence of renal and pituitary mediation. Metabolism 1981; 30: 129-134

[55] Lefebvre H, Dhib M, Godin M et al. Effect of the serotonin 5-HT4 receptor agonist cisapride on aldosterone secretion in corticotropic insufficiency and primary hyperaldosteronism. Neuroendocrinology 1997; 66: 229-233

[56] Ahmed AH, Calvird M, Gordon RD et al. Effects of two selective serotonin reuptake inhibitor antidepressants, sertraline and escitalopram, on aldosterone/renin ratio in normotensive depressed male patients. J Clin Endocrinol Metab 2011; 96: 1039-1045

[57] Contesse V, Hamel C, Lefebvre $\mathrm{H}$ et al. Activation of 5-hydroxytryptamine 4 receptors causes calcium influx in adrenocortical cells: involvement of calcium in 5-hydroxytryptamine-induced steroid secretion. Mol Pharmacol 1996; 49: 481-493

[58] Lenglet S, Louiset E, Delarue C et al. Activation of 5-HT(7) receptor in rat glomerulosa cells is associated with an increase in adenylyl cyclase activity and calcium influx through T-type calcium channels. Endocrinology 2002; 143: 1748-1760

[59] Louiset E, Duparc C, Lenglet S et al. Role of CAMP/PKA pathway and T-type calcium channels in the mechanism of action of serotonin in human adrenocortical cells. Mol Cell Endocrinol 2017; 441: 99-107

[60] Yabut JM, Desjardins EM, Chan E] et al. Genetic deletion of mast cell serotonin synthesis prevents the development of obesity and insulin resistance. Nat Commun 2020; 11: 463

[61] Seitz BM, Demireva EY, Xie H et al. 5-HT does not lower blood pressure in the 5-HT7 knockout rat. Physiol Genomics 2019; 51: 302-310

[62] Bharucha AE, Camilleri M, Haydock $S$ et al. Effects of a serotonin 5-HT(4) receptor antagonist SB-207266 on gastrointestinal motor and sensory function in humans. Gut 2000; 47: 667-674

[63] Smriga M, Torii K. L-Lysine acts like a partial serotonin receptor 4 antagonist and inhibits serotonin-mediated intestinal pathologies and anxiety in rats. Proc Natl Acad Sci USA 2003; 100: 15370-15375

[64] Duparc C, André C, Ménard J et al. I-Lysine acts as a serotonin type 4 receptor antagonist to counteract in vitro and in vivo the stimulatory effect of serotonergic agents on aldosterone secretion in man. Horm Metab Res 2017; 49: 269-275

[65] Lesouhaitier O, Feuilloley M, Lihrmann I et al. Localization of diazepam-binding inhibitor-related peptides and peripheral type benzodiazepine receptors in the frog adrenal gland. Cell Tissue Res 1996; 283: 403-412

[66] Lesouhaitier O, Feuilloley M, Vaudry H. Effect of the triakontatetraneuropeptide (TTN) on corticosteroid secretion by the frog adrenal gland. J Mol Endocrinol 1998; 20: 45-53

[67] Willenberg HS, Ansurudeen I, Schebesta K et al. The endothelium secretes interleukin-6 (IL-6) and induces IL- 6 and aldosterone generation by adrenocortical cells. Exp Clin Endocrinol Diabetes 2008; 116: (Suppl 1) S70-S74

[68] Aponte-López A, Fuentes-Pananá EM, Cortes-Muñoz D et al. Mast cell, the neglected member of the tumor microenvironment: Role in breast cancer. J Immunol Res 2018; 2018: 2584243

[69] Dyduch G, Kaczmarczyk K, Okoń K. Mast cells and cancer: Enemies or allies? Pol J Pathol 2012; 63: 1-7

[70] Strouch M], Cheon EC, Salabat MR et al. Crosstalk between mast cells and pancreatic cancer cells contributes to pancreatic tumor progression. Clin Cancer Res 2010; 16: 2257-2265

[71] Mao Y, Feng $Q$, Zheng $P$ et al. Low tumor infiltrating mast cell density confers prognostic benefit and reflects immunoactivation in colorectal cancer. Int J Cancer 2018; 143: 2271-2280
[72] Fu H, Zhu Y, Wang Y et al. Tumor Infiltrating Mast Cells (TIMs) Confers a Marked Survival Advantage in Nonmetastatic Clear-Cell Renal Cell Carcinoma. Ann Surg Oncol 2017; 24: 1435-1442

[73] Liao C-P, Booker RC, Brosseau J-P et al. Contributions of inflammation and tumor microenvironment to neurofibroma tumorigenesis. J Clin Invest 2018; 128: 2848-2861

[74] Mukai K, Tsai M, Saito H et al. Mast cells as sources of cytokines, chemokines, and growth factors. Immunol Rev 2018; 282: 121-150

[75] Hu G, Wang S, Cheng P. Tumor-infiltrating tryptase + mast cells predict unfavorable clinical outcome in solid tumors. Int J Cancer 2018; 142: 813-821

[76] Jachetti E, Cancila V, Rigoni A et al. Cross-talk between myeloid-derived suppressor cells and mast cells mediates tumor-specific immunosuppression in prostate cancer. Cancer Immunol Res 2018; 6: 552-565

[77] Białas M, Dyduch G, Szpor J et al. Microvascular density and mast cells in benign and malignant pheochromocytomas. Pol J Pathol 2012; 63: 235-242

[78] Visciano C, Prevete N, Liotti F et al. Tumor-associated mast cells in thyroid cancer. Int J Endocrinol 2015; 2015: 705169

[79] Ammendola M, Gadaleta CD, Frampton AE et al. The density of mast cells c-Kit + and tryptase + correlates with each other and with angiogenesis in pancreatic cancer patients. Oncotarget 2017; 8: 70463-70471

[80] Aiba M, Iri H, Suzuki $\mathrm{H}$ et al. Numerous mast cells in an 11-deoxycorticosterone-producing adrenocortical tumor. Histologic evaluation of benignancy and comparison with mast cell distribution in adrenal glands and neoplastic counterparts of 67 surgical specimens. Arch Pathol Lab Med 1985; 109: 357-360

[81] Marichal T, Tsai M, Galli SJ. Mast cells: potential positive and negative roles in tumor biology. Cancer Immunol Res 2013; 1: 269-279

[82] Boulkroun S, Samson-Couterie B, Dzib J-FG et al. Adrenal cortex remodeling and functional zona glomerulosa hyperplasia in primary aldosteronism. Hypertension 2010; 56: 885-892

[83] Zennaro M-C, Boulkroun S, Fernandes-Rosa F. Genetic causes of functional adrenocortical adenomas. Endocr Rev 2017; 38: 516-537

[84] Nanba K, Omata K, Gomez-Sanchez CE et al. Genetic characteristics of aldosterone-producing adenomas in blacks. Hypertension 2019; 73: 885-892

[85] Liu W, Shimada M, Xiao J et al. Nifedipine inhibits the activation of inflammatory and immune reactions in viral myocarditis. Life Sci 2009; 85: $235-240$

[86] Schjerning J, Uhrenholt TR, Svenningsen P et al. Histamine-dependent prolongation by aldosterone of vasoconstriction in isolated small mesenteric arteries of the mouse. Am J Physiol Heart Circ Physiol 2013; 304: H1094-H1102

[87] Xiao J, Shimada M, Liu W et al. Anti-inflammatory effects of eplerenone on viral myocarditis. Eur J Heart Fail 2009; 11: 349-353

[88] Lefebvre H, Cartier D, Duparc C et al. Characterization of serotonin(4) receptors in adrenocortical aldosterone-producing adenomas: in vivo and in vitro studies. J Clin Endocrinol Metab 2002; 87: 1211-1216

[89] Lampron A, Bourdeau I, Oble S et al. Regulation of aldosterone secretion by several aberrant receptors including for glucose-dependent insulinotropic peptide in a patient with an aldosteronoma. J Clin Endocrinol Metab 2009; 94: 750-756

[90] Ye P, Mariniello B, Mantero F et al. G-protein-coupled receptors in aldosterone-producing adenomas: a potential cause of hyperaldosteronism. J Endocrinol 2007; 195: 39-48

[91] Azizan EAB, Lam BYH, Newhouse S] et al. Microarray, qPCR, and KCNJ5 sequencing of aldosterone-producing adenomas reveal differences in genotype and phenotype between zona glomerulosa- and zona fasciculata-like tumors. J Clin Endocrinol Metab 2012; 97: E819-E829 
[92] Itcho K, Oki K, Kobuke K et al. Aberrant G protein-receptor expression is associated with DNA methylation in aldosterone-producing adenoma. Mol Cell Endocrinol 2018; 461: 100-104

[93] Zwermann O, Suttmann Y, Bidlingmaier M et al. Screening for membrane hormone receptor expression in primary aldosteronism. Eur J Endocrinol 2009; 160: 443-451

[94] Grunenwald S, Mazzuco TL, Mermejo LM et al. In vivo systematic screening for hormone receptors in primary aldosteronism reveals frequent aberrant hormone responsiveness. In: The Endocrine Society 92nd Annual Meeting. 2010; S1540

[95] Marner L, Gillings N, Madsen K et al. Brain imaging of serotonin 4 receptors in humans with [11C]SB207145-PET. Neurolmage 2010; 50: $855-861$
[96] Tavares AAS, Caillé F, Barret O et al. In vivo evaluation of 18F-MNI698: an $18 \mathrm{~F}$-labeled radiotracer for imaging of serotonin 4 receptors in brain. J Nucl Med 2014; 55: 858-864

[97] Tavares AAS, Caillé F, Barret O et al. Whole-body biodistribution and dosimetry estimates of a novel radiotracer for imaging of serotonin 4 receptors in brain: $\left[{ }^{18} \mathrm{~F}\right] \mathrm{MNI}-698$. Nucl Med Biol 2014; 41: 432-439

[98] Jolivet-Jaudet G, Inoue M, Takada K et al. Circannual changes in plasma aldosterone levels in Bufo japonicus formosus. Gen Comp Endocrinol 1984; 53: 163-167 